\title{
Electrically Conductive Spacers for self-cleaning membrane surfaces via periodic electrolysis
}

Hadeel Subhi Abid ${ }^{\mathrm{a}}$, Boor Singh Lalia ${ }^{\mathrm{b}}$, Paolo Bertoncello ${ }^{\mathrm{a}}$, Raed Hashaikeh ${ }^{\mathrm{b}}$, Ben Clifford ${ }^{\mathrm{c}}$, David T Gethin $^{\mathrm{c}}$ and Nidal Hilal ${ }^{\mathrm{a}^{*}}$

${ }^{a}$ Centre for Water Advanced Technologies and Environmental Research (CWATER), College of Engineering, Swansea University, UK

${ }^{\mathrm{b}}$ Chemical Engineering Department, Khalifa University of Science and Technology, Masdar Institute, Masdar City, P.O. Box 54224, Abu Dhabi, United Arab Emirates

${ }^{\mathrm{c}}$ Welsh Centre for Printing and Coating, College of Engineering, Swansea University, UK

*Corresponding author, Email: $\underline{\text { n.hilal@ @swansea.ac.uk }}$

\section{Submitted: April 2017}




\begin{abstract}
The use of an electrically conductive membrane has attracted significant interest in water treatment technology due to remarkable performance in fouling mitigation domain. In electrochemical systems, when external potential is applied, water electrolysis occurs and the generated gases efficiently clean the membrane surface. However, fabricating and integrating conductive membranes in current water treatment modules is challenging. The present work applies, for the first time, the electrolysis concept at the spacer component of the module rather than the membrane. Two types of materials were tested, a titanium metal spacer and a polymeric spacer. The polymeric spacer was made conductive via coating with a carbon-based ink comprised of graphene nanoplates (GNPs). A membrane system composed of the carbon coated/titanium metal spacer attached to the surface of a polyvinylidene fluoride (PVDF) microfiltration membrane and was assembled to the case of membrane module. The conductive spacers worked as an electrode (cathode) in electrochemical set-up. The membrane system was subjected to fouling and then exposed to periodic electrolysis, wherein in-situ cleaning of membrane surface by hydrogen bubbles generation at the spacer is applied.
\end{abstract}

Keywords: Membrane fouling; Conductive spacer; electrolysis; self-cleaning; bubble generation. 


\section{Introduction}

Membrane technology has been highlighted as a promising approach for water purification due to its essential advantages over other counterpart traditional technologies[1]. Constantly, a spacer is employed on the permeate side of the membrane in a module to improve the mechanical integrity of the membrane and allow efficient fluid flow[2]. The essential functions of a spacer mesh is to promote mass transfer and reduce concentration polarization [3]. In a study conducted by Vrouwenvelder et al.[4], it was demonstrated that in the presence of a feed spacer, the biofouling was much higher than when a feed spacer was absent. In a spiral-wound membrane systems, biofouling is dominantly a feed spacer problem. Many approaches have been reported on the modification spacers. Hausman et al. [5] stated their spacer modifications comprises engineering antibacterial polypropylene films via surface functionalization, in which a spacer charged with copper ions. Yang et al. [6] exhibited the coating both spacer and RO membrane with nano-silver, they stated that a higher permeate flux and rejection can be maintained. In addition, Araújo et al. [7] determined the potential of coated spacer and membrane with polydopamine and polydopamine-g-PEG as well as coated spacer with copper to control biofouling. They concluded that biofouling is not inhibited by employing polydopamine-coated, polydopamine-g-poly(ethylene glycol)-coated spacers and membranes, and a copper-coated spacer. In contrast, Miller et al. [8] evaluated by short-term batch protein and bacterial adhesion tests and employed the coated spacer and membrane by polydopamine and poly[ethylene glycol. Recently, Ronen et al. [9][10] revealed that biofouling could be restricted by modification of commercial polypropylene spacers via applying nano-zinc and/or nano-silver coated spacers sono-chemical deposition. An J. et al. [11] prepared hydrophobic spacer-mesh by polyaniline (PANI) coating on stainless mesh which was fabricated through an electrodepositing process to enhance surface hydrophobicity. The fabricated coated mesh films can be employed for frequent separation of organics and oil from water with highly potential selectivity, they also modified spacer film from hydrophobic to hydrophilic by electrodepositing of polypyrrole(PPy) at various electric potential to enhance mesh surface morphology for selective absorption and purification. Sun et al.[12] reported an approach for the modification of commercially stainless-steel mesh, wherein a layer-by-layer graphene assembly technique was adopted. They stated that their approach may considerably enhance traditional separation system performance and improve removal of organic compounds and oil from water. Darmanin T. and Guittard F.[13] investigated computationally the performance of electrodeposition of nano-materials on metal mesh substrates and their impact on the surface hydrophilicity, which can employed in applications of water transportation and bio-sensing systems. A summary of modified coating spacers with materials shown in the literature is presented in Table 1.

Table 1:Modified coating spacer, to enhance traditional separation system performance.

\begin{tabular}{|l|l|l|l|}
\hline Material & functionalization technique & Application & References \\
\hline Copper & $\begin{array}{l}\text { functionalization of } \\
\text { polypropylene (PP) films by } \\
\text { a metal chelating spacer } \\
\text { charged with copper ions }\end{array}$ & $\begin{array}{l}\text { copper ions were employed } \\
\text { to disinfect water from } \\
\text { microbial biofilms }\end{array}$ & {$[5]$} \\
\hline Nano-sliver & $\begin{array}{l}\text { Coating the RO membrane } \\
\text { and spacer with nano-silver } \\
\text { particles }\end{array}$ & $\begin{array}{l}\text { Permeate flux decline and } \\
\text { salt rejection and the effect } \\
\text { of silver-coated spacer on } \\
\text { antimicrobial activity }\end{array}$ & {$[6]$} \\
\hline
\end{tabular}




\begin{tabular}{|c|c|c|c|}
\hline $\begin{array}{l}\text { Polydopamine } \\
\text { polydopamine- } \\
\text { g-PEG } \\
\text { copper } \\
\end{array}$ & $\begin{array}{l}\text { (i) Polydopamine and } \\
\text { polydopamine-g-PEG coated } \\
\text { spacers and membranes, (ii) } \\
\text { a copper-coated spacer }\end{array}$ & To control biofouling & [7] \\
\hline $\begin{array}{l}\text { Polydopamine } \\
\text { polydopamine- } \\
\text { g poly } \\
\text { (ethylene } \\
\text { glycol) }\end{array}$ & $\begin{array}{l}\text { Polydopamine and } \\
\text { polydopamine-g-PEG coated } \\
\text { spacers and membranes }\end{array}$ & $\begin{array}{l}\text { To defouling bovine serum } \\
\text { albumin, as a model } \\
\text { protein, and Pseudomonas } \\
\text { aeruginosa, } \\
\text { as model Gram-negative } \\
\text { bacterium. }\end{array}$ & {$[8]$} \\
\hline $\begin{array}{l}\text { zinc oxide } \\
\text { nanoparticles }\end{array}$ & $\begin{array}{l}\text { commercial polypropylene } \\
\text { spacer modification through } \\
\text { sono-chemical deposition }\end{array}$ & $\begin{array}{l}\text { To suppress biofilm - } \\
\text { formation }\end{array}$ & [9] \\
\hline $\begin{array}{l}\text { Nano-sliver } \\
\text { partials }\end{array}$ & $\begin{array}{l}\text { commercial polypropylene } \\
\text { spacer functionalization via } \\
\text { sono-chemical deposition }\end{array}$ & $\begin{array}{l}\text { To hinder biofouling } \\
\text { development }\end{array}$ & [10] \\
\hline $\begin{array}{l}\text { polyaniline } \\
\text { (PANI) }\end{array}$ & $\begin{array}{l}\text { PANI- coating on stainless } \\
\text { through an electrodepositing } \\
\text { technique }\end{array}$ & $\begin{array}{l}\text { To enhance surface } \\
\text { hydrophobicity and } \\
\text { frequent separation of } \\
\text { organics and oil from water }\end{array}$ & {$[11]$} \\
\hline $\begin{array}{l}\text { Polypyrrol } \\
\text { (ppy) }\end{array}$ & ppy-electrodeposition & $\begin{array}{l}\text { To improve mesh surface } \\
\text { morphology and selectivity }\end{array}$ & \\
\hline graphene & $\begin{array}{l}\text { layer-by-layer method } \\
\text { graphene assembly via a dip- } \\
\text { coating method }\end{array}$ & $\begin{array}{l}\text { To improve separation or } \\
\text { organic compounds } \\
\text { selectivity absorption from } \\
\text { water }\end{array}$ & [12] \\
\hline $\begin{array}{l}\text { PolyNaphDOT } \\
\text { (Monomer) }\end{array}$ & $\begin{array}{l}\text { Employing electro- } \\
\text { polymerization method on } \\
\text { stainless steel mesh } \\
\text { substrates to induce the } \\
\text { nanotubes }\end{array}$ & $\begin{array}{l}\text { This mechanism can be } \\
\text { benefit in oil/water } \\
\text { separation membranes }\end{array}$ & {$[13]$} \\
\hline
\end{tabular}

Among methods to enhance membrane de-fouling performance, much focus has been shifted towards a combined electrochemical system with membrane water treatment processes. An alternative non-destructive, affordable and energy efficient membrane fouling mitigation techniques are required to adopted. This relatively novel approach improved fouling control via either foulants oxidation [14][15] or bubble generation [16][17]. However, from the engineering view point, in-situ membrane fouling control is highly desirable but seems very challenging [18]. Electrolysis is a technique used to produce $\mathrm{H}_{2}$ bubbles from water, in which this is a procedure of decomposition water to the both hydrogen and oxygen, when a potential is applied across the cell. For this purpose, an electrochemical cell is used and it is composed of anode and cathode electrodes separated by solution, which acts as an electrolyte. Traditionally, the mechanism of cleaning during the electrolysis process is due to the microbubbles generation at the surface of electrically conductive membrane surface, wherein electrolysis of an aqueous $\mathrm{NaCl}$ solution to hydrogen gas at the conductive membrane (at the cathode) and chlorine gas is produced at an electrode (at the anode), according to the following equations: 
The formed hydrogen microbubbles detach the foulants out of the membrane surface to the feed stream [19]. For any additional electrical energy is demanded in terms of overcoming the over-potential that stemming from activation and losses of ohmic within the cell. Electrolysis can be performed with low temperatures less than $100{ }^{\circ} \mathrm{C}[20]$. It was found that the bubbles, generated at the conductive membrane surface (at cathodic electrode), performance, as a physical barrier and can mitigate the foulants deposited at membrane surface during filtration processes[21][22][23]. Figure 1 illustrates the mechanism of self-cleaning conductive substrate via bubble generation.
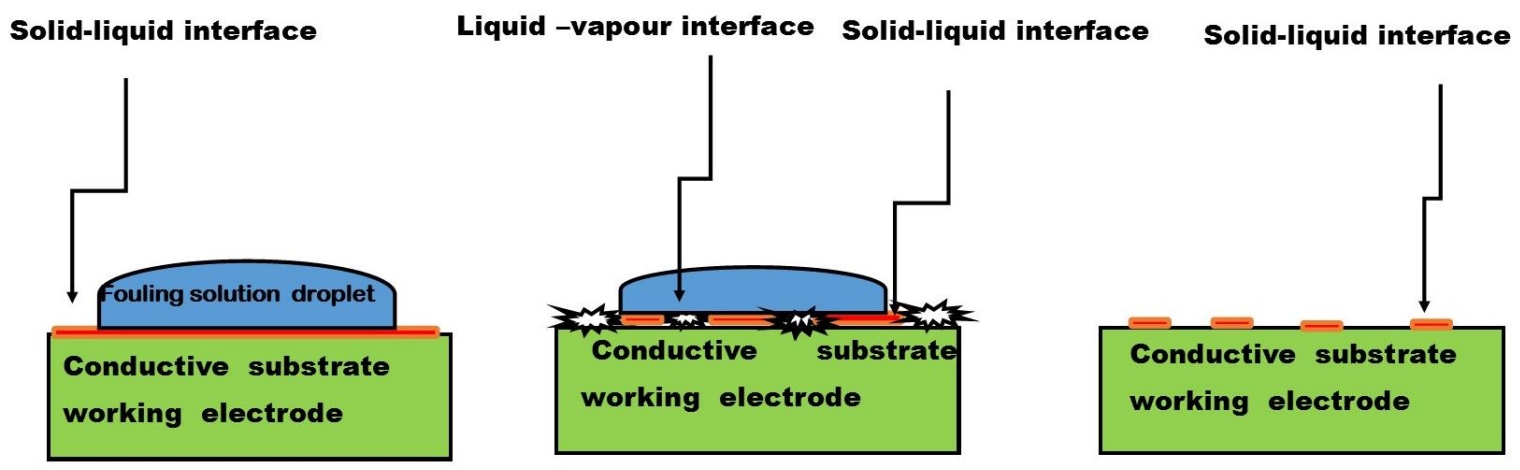

Figure 1: Mechanism of defouling by generated bubbles, (a) fouling drop adsorption, (b) electrochemical treatment and (c) generated bubble defouling [21].

Ahmid et al [24] stated through the electrolysis process at the solid-liquid (electrode-electrolyte interface), gas bubbles generate at the electrode surface and when their size be appropriate, they begin to move away from the electrode surface. The gas bubble long stay on the electrode surface lowers the charge transfer reaction at the solid -liquid interface and eventually leads to reduction in the electrolysis process efficiency. Sun et al.[25] presented a comparison by adopting three kinds of electrically-driven anti-fouling mechanisms for the horizontally aligned CNT membranes, so-called electro-reduction electro-oxidation, and ionic-pump in. Both of (BSA) and napthalene (protein solutions) were employed as foulants model. In term of using foulant model, they found that both electrochemical oxidation and/or reduction reaction were effectively in-situ biomolecule de-foulants CNT-membranes. Nevertheless, they concluded that the electro-oxidation reaction is remarkably appropriate to the specific number of cycles when potently absorbed foulants are comprised. Wu et al. [21] stated that nanobubbles can be utilized to inhibit the adsorption of proteins as well as to remove the adsorbed foulants. Nanobubbles with a regular size and density were generated on graphite surfaces, wherein electrochemically controlled by the applied current. It was found that prior to exposure the surface to BSA solution, and with $20 \mathrm{~s}$ electrochemically pre-treatment for to the surface enhanced performance and lowered protein coverage to 26-34\%. On a conductive surface, preadsorbed protein was also prevented by generation of nanobubbles, in which the nanobubbles are produced at the substrate surface and performance as barrier to the foulants layer. Correspondingly, the adsorbed protein was pushed from the solid-liquid to the liquid-vapour interface because of the bubbles growing. Thus, with a lower shear water-stream, the foulants could be readily detached (Figure 1). Hashaikeh et al [19] proposed an approach allows in-situ 
membrane self-cleaning, in which inorganic and biological fouling categories mitigation have been achieved. These adopted cleaning mechanisms comprising micro-bubbles generation at MWCNTs coated membranes surface printed with nano sliver ink acts as a spacer during electrolysis. They stated that. in present of an aqueous $\mathrm{NaCl}$ solution, gas of hydrogen is formed at the conductive membrane surface, which performs as a cathode and at the same time gas of chlorine is formed at a stainless-steel electrode, which performance as an anode, wherein formed hydrogen microbubbles push back the deposited foulants away from the surface of membrane into the flow stream. The consequence of filtration cycle duration on the recovery of flux was studied by Lalia et al.[17] who tested the cleaning efficiency of an electrically conductive nanocomposite CNS/PVDF membranes with filtration of a yeast suspension via applying periodic electrolysis at $2 \mathrm{~V}$ for $2-3 \mathrm{~min}$. They found that the flux was reduced to $40 \%$ of its initial value after $4.6 \mathrm{~h}$ filtration period time. Farah et al.[24] used periodic electrolysis technique with self-supporting NC/CNS membranes through cathodic hydrogen bubble generation that keeping flux higher than $100 \mathrm{~L} / \mathrm{m}^{2} \mathrm{~h}$ with $60 \%$ recovery for $\mathrm{MgSO}_{4}$ and $47 \%$ for $\mathrm{CaCl}_{2}$ due to cathodic hydrogen bubbles generation. They found that bubble generation at the modified conductive membrane surface due to electro-reduction is considered optimum technique for self-cleaning membrane for a sizeable number of cycles, once it does not impair membrane surface. A summary of electrolysis applications for self-cleaning conductive substrate by hydrogen bubble formation technique is shown in Table 2.

Table 2. Application electrolysis to produce hydrogen bubbles from water.

\begin{tabular}{|l|l|l|l|}
\hline Cathode & Application & $\begin{array}{l}\text { hydrogen bubbles } \\
\text { Performance }\end{array}$ & Reference \\
\hline graphite surfaces & $\begin{array}{l}\text { generation } \\
\text { hydrogen } \\
\text { bubbles }\end{array}$ & $\begin{array}{l}\text { barrier to the foulants } \\
\text { layer(protein-BSA) }\end{array}$ & {$[21]$} \\
\cline { 1 - 1 } $\begin{array}{l}\text { MWCNTs coated } \\
\text { membrane }\end{array}$ & $\begin{array}{l}\text { via } \\
\text { electrolysis } \\
\text { process }\end{array}$ & $\begin{array}{l}\text { push back the deposited foulants } \\
\text { (CaCO } 3 \text { and yeast) away from } \\
\text { the surface of membrane }\end{array}$ & {$[19]$} \\
\cline { 1 - 1 } $\begin{array}{l}\text { Nanocomposite CNS/PVDF } \\
\text { membranes }\end{array}$ & $\begin{array}{l}\text { Cleaning membrane from a yeast } \\
\text { suspension }\end{array}$ & {$[17]$} \\
\cline { 1 - 1 } $\begin{array}{l}\text { self-supporting NC/CNS } \\
\text { membranes }\end{array}$ & $\begin{array}{l}\text { Remove } 60 \% \text { for } \mathrm{MgSO}_{4} \text { and } \\
47 \% \text { for } \mathrm{CaCl}_{2}\end{array}$ & {$[24]$} \\
\hline
\end{tabular}

Despite huge focus devoted, so far, to the applications of electrolysis in pressure-driven membrane technologies using conductive membranes, no research has been reported in the literature on the use of conductive spacers. In this study we report, for the first time, the use of conductive spacer in place of conductive membrane to achieve the in-situ fouling removal. The implementation of conductive spacer in the existing separation technology is quite simple compared to replacement of the conventional membrane with the conductive membrane which are not commercialized so far. In this paper, we have investigated the possibility of the application of the electrolysis technique via modified plastic spacer, which was employed for in-situ cleaning, when membrane modules located underneath it. The spacer-mesh has been coated with a thin nano-carbon black ink layer via a dip-coating method and acts as a cathode 
during the periodic electrolysis process. The efficiency of self-cleaning has been studied during filtration of sodium alginate suspension, which is typical organic membrane foulant for membrane-based water treatment processes. We demonstrate that at applied constant potential of $-6 \mathrm{~V}$ for only $2 \mathrm{~min}$ on conductive spacer-PVdF/MF membrane, sodium alginate fouling can be reduced and the enhancement in relative flux can be noticed. The potentiostat instrument model CH760 E is employed for Cyclic Voltammetry (CV) and Linear Sweep Voltammetry (LSV) (see Figure 2). For any additional electrical energy is demanded during electrochemical experimental is in term of overcoming the over-potential that stemming from activation and losses of ohmic loses within the cell.

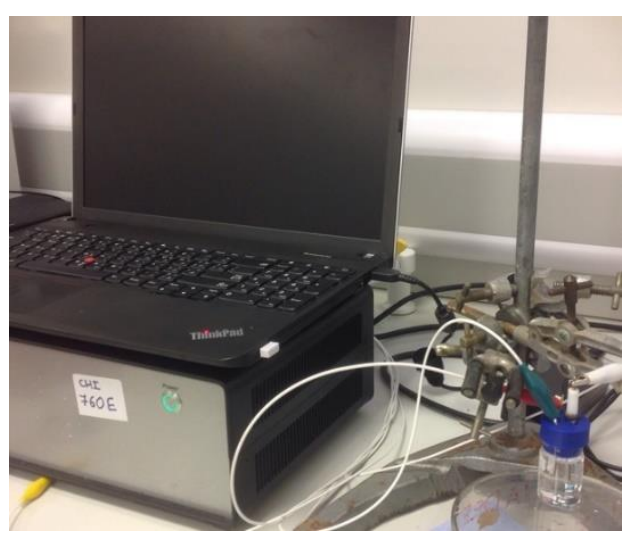

(a)

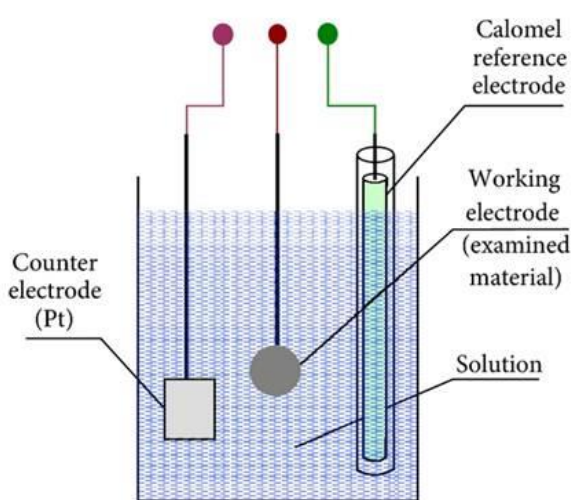

(b)

Figure 2: The potentiostat instruments model CH760 E device is used for Cyclic Voltammetry (CV) and Linear Sweep Voltammetry (LSV).

\section{Materials and Method}

\subsection{Materials}

Microfiltration PVDF membranes (Millipore, GSWP, $0.22 \mathrm{~mm}$ ), sodium chloride, sodium alginate, sodium dodecylbenzene sulfonate -(SDBS) (Sigma Aldrich, UK) were used as received. Plastic mesh with aperture $3 \times 3 \mathrm{~mm}, 45^{0}$ (GE, USA) was used as a plastic spacer, titanium spacer (Good fellow company).

\subsection{Mesh Coating}

Plastic spacer with $3 \times 3 \mathrm{~mm}$ apertures was pre-treated with SDBS-surfactant in ultrasonic bath for $15 \mathrm{~min}$ at $20{ }^{\circ} \mathrm{C}$ and dried in air. The treated mesh was coated with the carbon ink high solids loading comprising Graphene Nano-Platelets (GNP's) using dipped coating method, in a proprietary resin system where such system exhibit sheet resistance in the range of $118 \Omega / \mathrm{Sq}$. Following the coating process, the spacer was hung in a Votsch VTL 60/90 convection oven set to $70^{\circ} \mathrm{C}$ for 10 minutes to evaporate any solvent remaining in the sample and act as a curing process making the coated layer conductive. The carbon coated spacer was kept at room temperature for a period of at least 12 hours prior to testing. An optical image of the coated spacer is shown in Figure 3. The coating method employed is easily scalable to mass 
manufacture if required and a volume manufacturing could be achieved using a reel to reel process design.

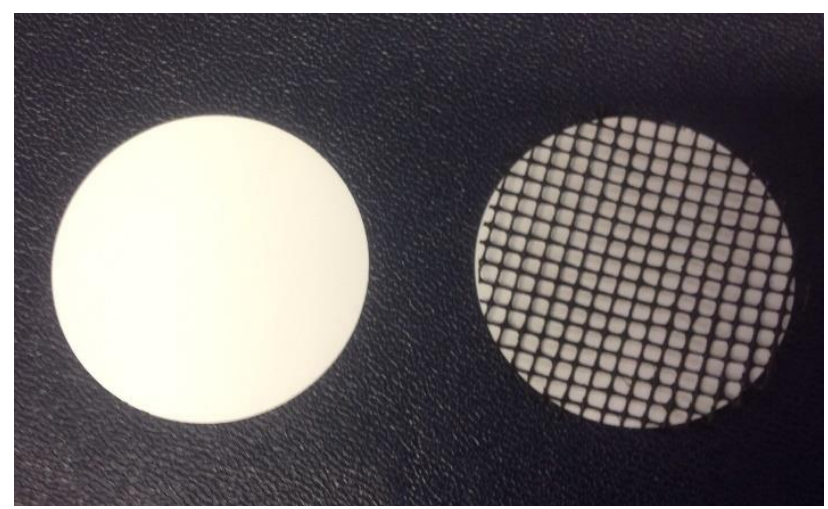

(a)

(b)

Figure 3: Optical image of (a) microfiltration PVdF membrane (b) the black carbon coated spacer combined with microfiltration PVdF membrane, wherein each mesh grid dimension of $3 \times 3 \mathrm{~mm}, 45^{\circ}$.

\subsection{Electrochemical Analysis}

Electrolysis behaviour of the titanium mesh and conductive spacer was examined by linear sweep voltammetry (LSV) and cyclic voltammetry (CV) using $\mathrm{CH} 760 \mathrm{E}$ potentiostat. The three-electrode system have been employed to evaluated performance of coated spacer, conductive spacer acts as working electrode, platinum wire as a counter current electrode (anode), meanwhile $\mathrm{Ag} / \mathrm{AgCl}(3.5 \mathrm{M} \mathrm{KCl})$ acts as a reference electrode in $0.5 \mathrm{M} \mathrm{H}_{2} \mathrm{SO}_{4}$ acidic media with scanning rate of $0.05 \mathrm{~V} / \mathrm{s}$. Surface morphology of the coated carbon spacer before and after electrolysis has been studied with scanning electron microscope (SEM) (HitachiS4800) as shown in Figure 4. It is clear from Figure 4-a that homogeneous coating was achieved due to the steady spread of coating on surface of the spacer. Comparison between both images, after application of electrolysis during self-cleaning process, shows is no damage to the structure of the coating observed on the surface even though it is known that the current density is a factor leads to crack coating. It is also worth noting that the electrolysis has not affected the spacer coating.

Membranes performance was estimated in terms of pure water flux WFT, organic solution flux, and organic foulants rejection. The permeation experiments of the MF membranes were carried out using a cross-flow filtration cell at $0.5 \mathrm{bar}$ and at room temperature. The membranes were evaluated at a pressure of 0.5 bar for $1 \mathrm{~h}$ using distillate water to gain a constant flux. After that water flux $\left(\mathrm{J}_{\mathrm{w}}\right)$ was determined at a trans-membrane pressure of 0.5 bar using filtration cell [26].

$$
J w=\frac{V}{A \Delta t}
$$

Where $\mathrm{V}$ is the volume of filtrate collected, $\Delta \mathrm{t}$ is the filtration time and $\mathrm{A}$ is geometric active area in electrochemical cell. Also, the typical organic fouling rejection (30\%) was calculated using[27]: 
$\mathrm{Rj}=\left(1-\frac{\mathrm{Cp}}{\mathrm{Cf}}\right) \times 100$

where $\mathrm{C}_{\mathrm{p}}$ and $\mathrm{C}_{\mathrm{f}}$ are the sodium alginate contents in the permeate and feed solutions, respectively $(\mathrm{ppm})$; these were measured via using a TOC-L device .

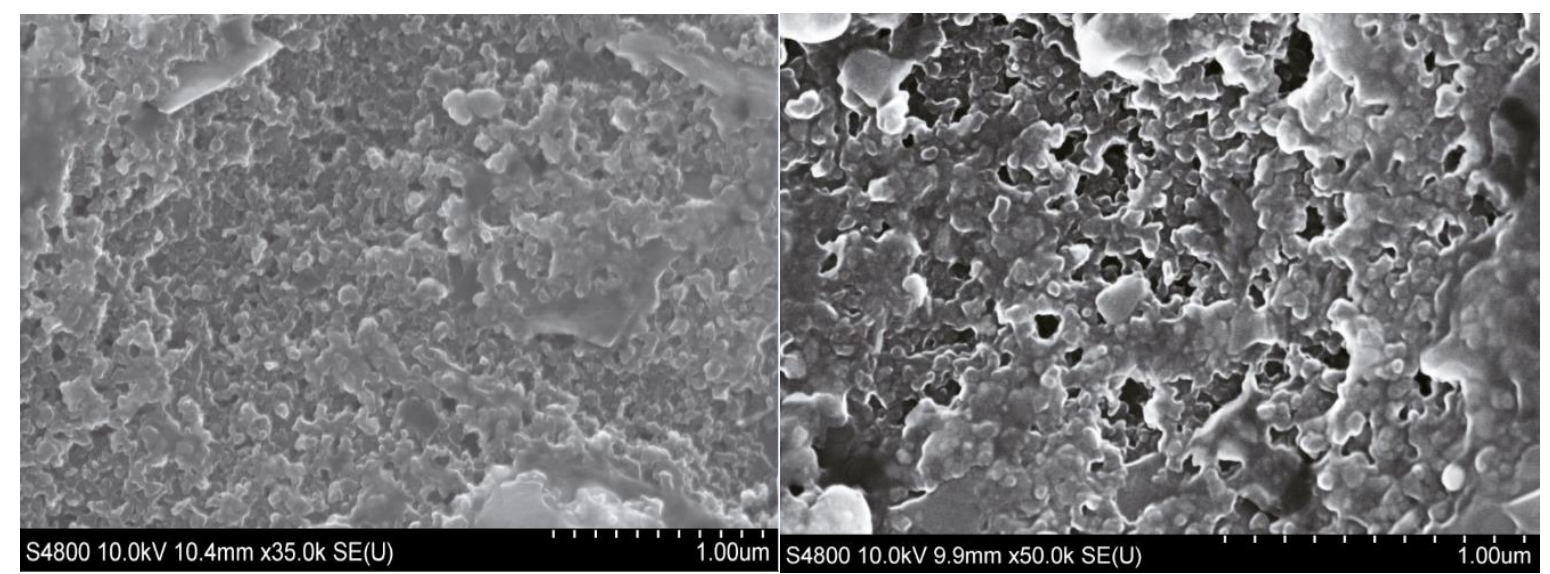

(a)

(b)

Figure 4: SEM surface morphology of the conductive coatings mesh (a) before and (b) after electrolysis process applied in filtration system.

\subsection{Cross-flow filtration Setup}

A customised a polycarbonate cross-flow filtration cell with an effective filtration area 10.2 $\mathrm{cm}^{2}$ was designed by including an electrically conductive module as shown in Figure 5, a schematic of cross-flow filtration experiment is shown in Figure 6. Conductive spacer was served as a cathode in electrochemical system, the graphite electrode of diameter $15 \mathrm{~mm}$ as an anode. The electrolysis process was stated at constant potential of $-6 \mathrm{~V}$ for $2 \mathrm{~min}$, wherein the filtration process was stopped during electrolysis in every run. Sodium alginate was employed as model foulant to evaluate performance of antifouling in filtration system. The feed solution used in this study contains 20 -ppm sodium alginate $10,000 \mathrm{ppm} \mathrm{NaCl}, \mathrm{NaCl}$ solution was used to assist the electrolysis process during in-situ fouling mitigation. The feed solution was filtrated through conductive spacer-membrane at operating pressure of 0.5 bar with a flow rate of $0.58 \pm 0.01 \mathrm{~L} / \mathrm{min}$. The potential was applied for $2 \mathrm{~min}$ after 30,45 and 60 interval time followed by another filtration, the collected permeate weighted with time to calculate the permeation flux. 


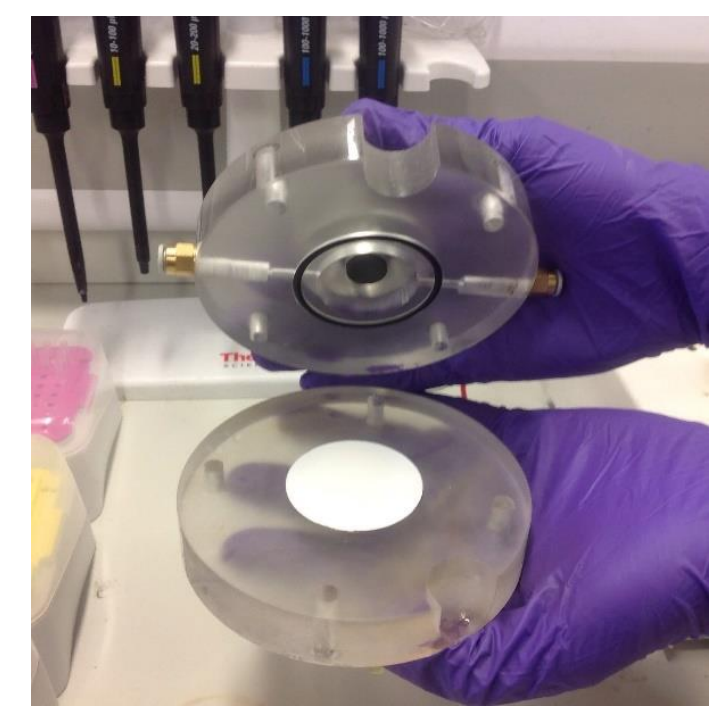

Figure 5: Enhanced filtration Cell is used for filtration process.

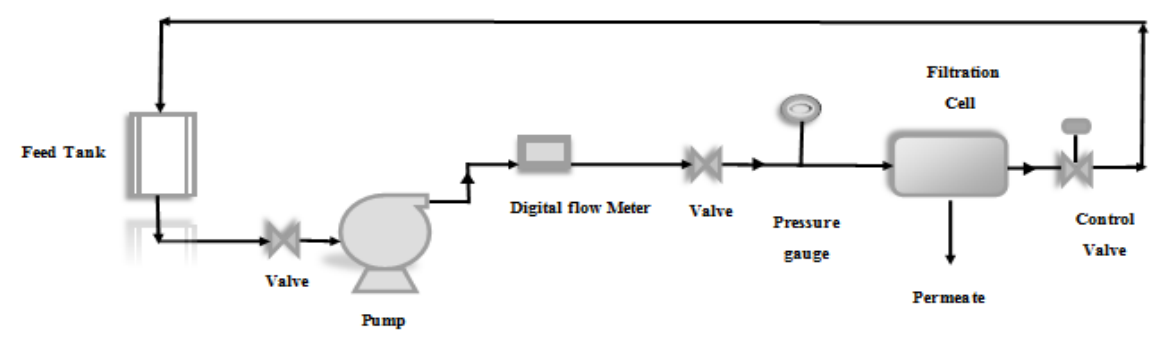

Figure 6: Schematic representation of the enhanced cross-flow set-up.

\section{Results and discussion}

The electrochemical activity of the carbon coated spacer and titanium metal spacer is studied for both linear sweep and cyclic voltammetry technique. Figure 7 shows a comparison of the electrochemical behaviour between both Titanium metal spacer and carbon coated spacer. The figure reveals that hydrogen gas evolution on carbon coated spacer stated at $-0.81 \mathrm{~V}$ (vs $\mathrm{Ag} / \mathrm{AgCl}$ reference) compared to $-0.5 \mathrm{~V}$ with the titanium metal spacer. The results indicated that a high overpotential is needed for the carbon coated spacer compared with titanium spacer. 


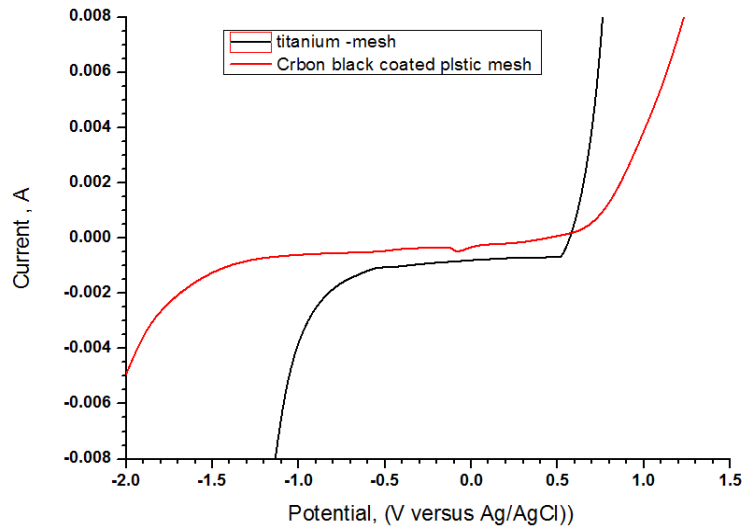

(a)

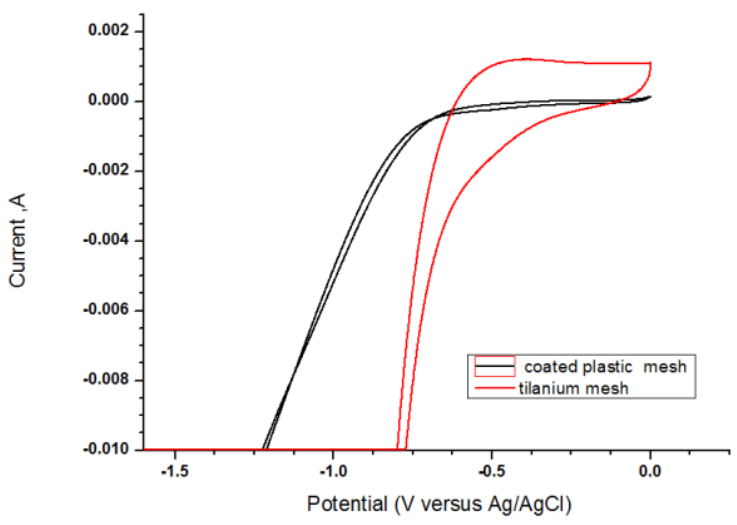

(b)

Figure 7: (a) Linear sweep voltammetry (LSV) of both conductive titanium metal and carbon coated spacer and (b) Cyclic voltammetry (CV) of both conductive titanium metal and carbon coated spacer.

The in-situ cleaning behaviour of both carbon coated spacer and titanium metal spacer using typical sodium alginate suspension of $20 \mathrm{ppm}$ as an organic foulant was evaluated at different interval filtration time at an operation pressure of 0.5 bar as a function of time (Figures8, 9, 10). Figure 8-a demonstrates the performance of carbon coated spacer combined with PVDF membrane during filtration of sodium alginate aqueous solution. It can be noticed from this figure that the normalized flux declined from 1 to 0.0172 after a filtration period of $200 \mathrm{~min}$ without electrolysis. For in-situ cleaning experiment, the suspension was filtrated through carbon coated spacer/PVDF membrane for $30 \mathrm{~min}$ interval time and the relative flux declined to 0.668 . The electrolysis cleaning was performed by applying a potential of $-6 \mathrm{~V}$ for 2 min to the carbon coated spacer leading to an enhancement in the relative flux from 0.668 to 0.988 . Again, after another 30-min filtration time the relative flux reached 0.108. However, when applied electrolysis for $2 \mathrm{~min}$, the relative flux from 0.108 to 0.983 . After $90 \mathrm{~min}$ of filtration, the relative flux declined to a value of 0.045 and again improved to 0.7492 with 2 min electrolysis. After $120 \mathrm{~min}$ ( ${ }^{\text {th }}$ interval filtration time), the relative flux dropped to 0.0368 and again 2 min electrolysis enhanced it to 0.529 . While for the $5^{\text {th }}$ interval filtration time $(150$ $\mathrm{min}$ ), the relative flux declined to 0.03 and further application of electrolysis for $2 \mathrm{~min}$ increased it to 0.393 . Finally, after completing the $6^{\text {th }}$ interval filtration time $(180 \mathrm{~min})$, the relative flux reached to 0.025 and improved with $2 \mathrm{~min}$ electrolysis to 0.272 . The enhancement of relative flux is gained due to surface cleaning by applying electrolysis run for 2 min between each interval filtration. Similar trend is observed when using Titanium metal spacer for the same interval time as shown in Figure 8-b. 


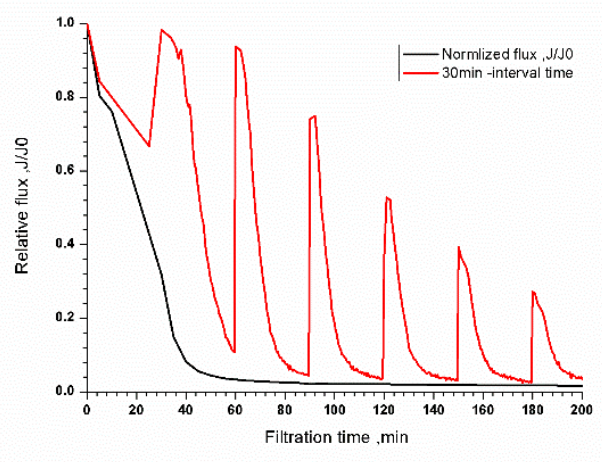

(a)

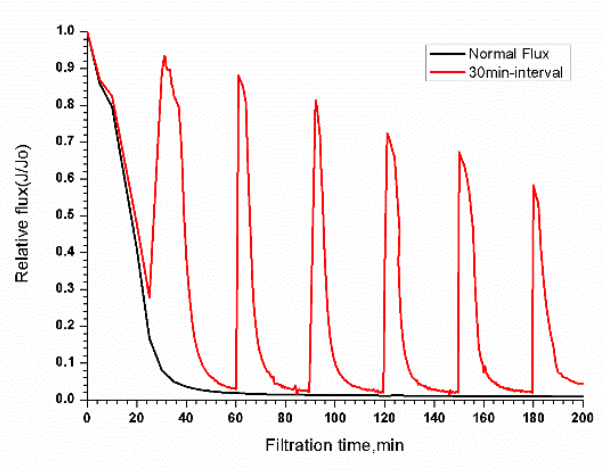

(b)

Figure 8: Normalized flux versus filtration time duration at filtration of sodium alginate suspension through carbon coated spacer/PVDF membrane: without electrolysis, and with 2 min electrolysis after filtration intervals of every $30 \mathrm{~min}$ (a) carbon coated spacer (b) titanium metal spacer.

The effect of filtration cycle time on the flux recovery was also performed via electrolysis cleaning after 45 min and 60 min filtration intervals time as shown in Figure 9 and Figure 10. When employing the first electrolysis cleaning the relative flux increased from 0.062 to 0.857 with 45 min interval filtration time and after the second cleaning from 0.033 to 0.563 with 90 min. It also increased from 0.026 to 0.453 after third cleaning and from 0.02 to 0.248 after fourth cleaning.

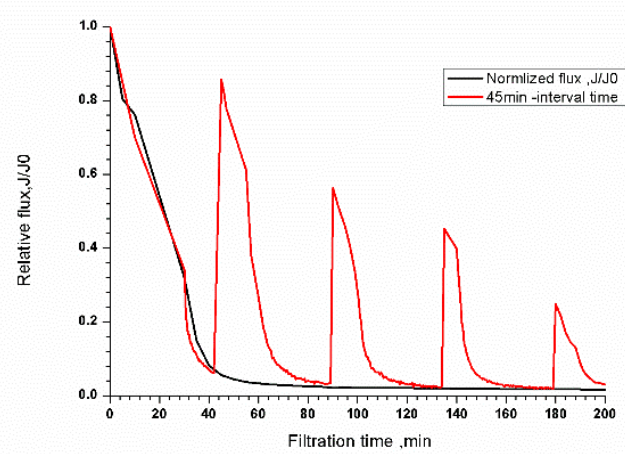

(a)

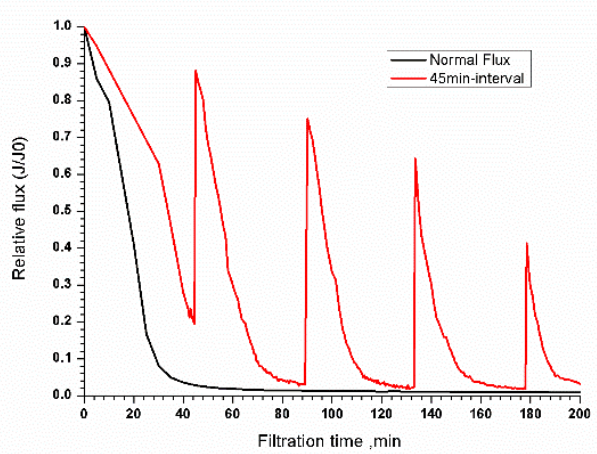

(b)

Figure 9: Normalized flux versus filtration time duration at filtration of sodium alginate. suspension through combined carbon coated spacer/PVDF membrane: without electrolysis, and with 2 min electrolysis after filtration intervals of every 45 min (a) carbon coated Spacer and (b) Titanium metal spacer.

Similar permeation flux improvement was detected, when the periodic electrolysis was applied after 60 min interval time as shown in Figure 10. Figure 10-a show results on the carbon coated spacer where a subsequent enhancement in relative flux from 0.039 to 0.49 , from 0.024 to 0.49 and from 0.01216 to 0.2576 were observed after 60, 120 and 180 min interval filtration period respectively when a 60-min filtration cycle experiment was employed. A comparison between the three filtration cycles $(30,45$ and $60 \mathrm{~min}$ ) reveals a higher flux recovery when shorter electrolysis cleaning cycle is applied. This is most probably due to a loose foulant layer on the surface and therefore easier to mitigate from both membrane and spacer surfaces compared with the denser foulants deposited layers at pro-longed filtration. 


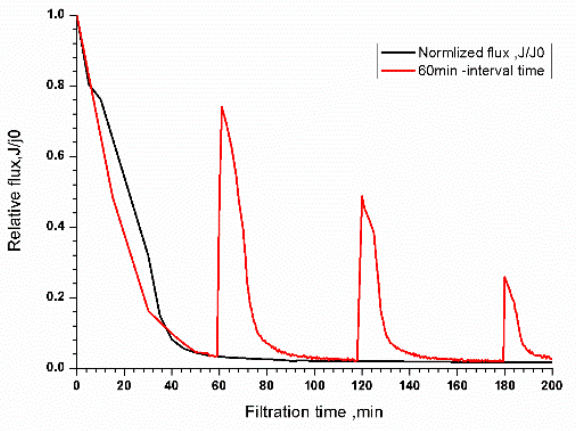

(a)

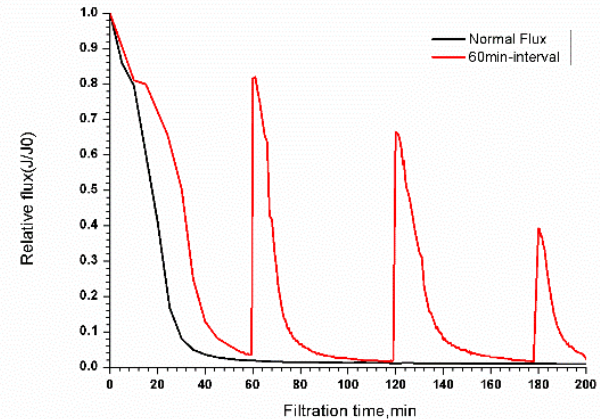

(b)

Figure 10: Normalized flux versus filtration time duration at filtration of sodium alginate suspension through combined carbon coated spacer/PVDF membrane: without electrolysis, and with 2 min electrolysis after filtration intervals of every 60 min (a) carbon coated spacer and (b) titanium metal spacer.

Figure 11 shows the enhanced relative flux value gained after each interval (a:30 min, b:45 min, c:60min) for both Titanium spacer and coated polymeric spacer. The coated polymeric spacer relative flux shows higher value at $30 \mathrm{~min}$ and $60 \mathrm{~min}$ at interval time of $30 \mathrm{~min}$ at the beginning of the operation while the Titanium spacer shows better values at prolonged operation. This is more attributed to the fact that the Titanium spacer is more electrically stable than the coated polymeric spacer.

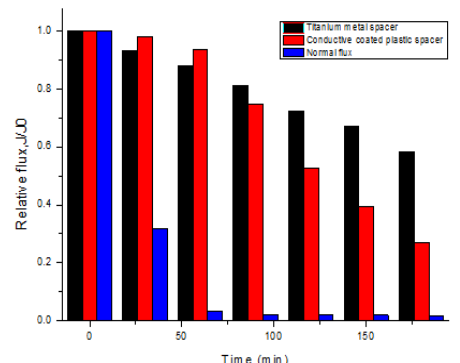

(a)

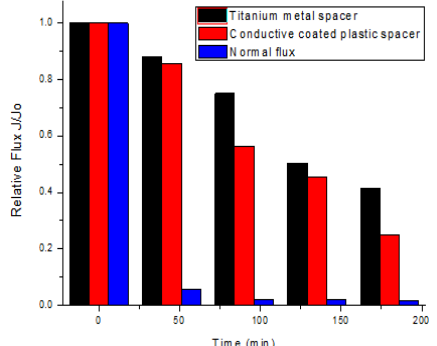

(b)

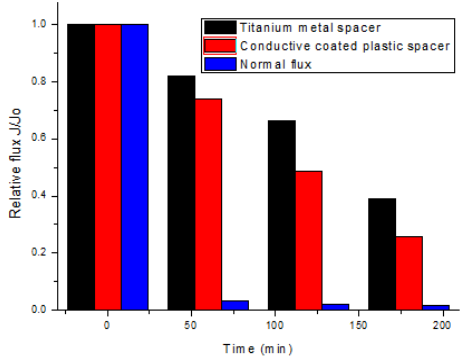

(c)

Figure 11: Comparison between relative flux values gained after each interval for both titanium spacer and carbon coated spacer. (a) 30 min interval filtration, (b) 45 min interval filtration and (c) 60 min interval filtration.

\section{Conclusion}

In this study, an in-situ cleaning technique was developed based on the concept of periodic electrolysis using commercial PVDF microfiltration membrane. Spacers were made of metal titanium or carbon coated polymeric mesh. A membrane/spacer system was assembled, where PVDF-MF membrane was attached to the spacer in cross-flow cell. The cleaning efficiency of the PVDF microfiltration membrane was investigated by filtration of a sodium alginate suspension. The membrane cleaning procedure was conducted in an electrochemical system, wherein the conductive spacer performed as a cathode and a graphite electrode acted as a counter electrode (anode). Applied potential leads to the generation of micro-bubbles on the spacer net, which allows the membrane to in-situ mitigate foulants and improve the flux via consequent cycles. The main advantage of this cleaning technique is that it tackles the membrane fouling problem with high efficiency with periodic treatment without addition to 
chemical reagents or need for backwash cleaning which shortens the life span of the membrane modules. Furthermore, electrically conductive spacers can be easily integrated with all pressure driven membrane types including: MF, UF, NF and RO modules. Application of electrically conductive spacer for in-situ self-cleaning membrane processes will enhance the membrane module performance.

\section{References}

[1] B.S. Lalia, V. Kochkodan, R. Hashaikeh, N. Hilal, A review on membrane fabrication: Structure, properties and performance relationship, Desalination. 326 (2013) 77-95..

[2] H.J. Tanudjaja, W. Pee, A.G. Fane, J. Wei, Effect of spacer and cross fl ow velocity on the critical fl ux of bidisperse suspensions in micro fi ltration, 513 (2016) 101-107..

[3] T. Tran, B. Bolto, S. Gray, M. Hoang, E. Ostarcevic, An autopsy study of a fouled reverse osmosis membrane element used in a brackish water treatment plant, 41 (2007) 3915-3923..

[4] J.S. Vrouwenvelder, D.A. Graf von der Schulenburg, J.C. Kruithof, M.L. Johns, M.C.M. van Loosdrecht, Biofouling of spiral-wound nanofiltration and reverse osmosis membranes: A feed spacer problem, Water Res. 43 (2009) 583-594. doi:10.1016/j.watres.2008.11.019.

[5] R. Hausman, T. Gullinkala, I.C. Escobar, Development of Low-Biofouling Polypropylene Feedspacers for Reverse Osmosis, 114 (2009) 3068-3073. doi:10.1002/app.

[6] H. Yang, J.C. Lin, C. Huang, Application of nanosilver surface modification to RO membrane and spacer for mitigating biofouling in seawater desalination, Water Res. 43 (2009) 3777-3786. doi:10.1016/j.watres.2009.06.002.

[7] P.A. Araújo, D.J. Miller, P.B. Correia, M.C.M. Van Loosdrecht, J.C. Kruithof, B.D. Freeman, et al., Impact of feed spacer and membrane modi fi cation by hydrophilic, bactericidal and biocidal coating on biofouling control, DES. 295 (2012) 1-10. doi:10.1016/j.desal.2012.02.026.

[8] P.B. Correia, M.M. Ramsey, D.J. Miller, P.A. Arau, J.C. Kruithof, M.C.M. Van Loosdrecht, et al., Short-term adhesion and long-term biofouling testing of polydopamine and poly ( ethylene glycol ) surface modifications of membranes and feed spacers for biofouling control, 6 (2012). doi:10.1016/j.watres.2012.03.058.

[9] A. Ronen, R. Semiat, C.G. Dosoretz, Impact of $\mathrm{ZnO}$ embedded feed spacer on biofilm development in membrane systems, Water Res. 47 (2013) 6628-6638. doi:10.1016/j.watres.2013.08.036.

[10] A. Ronen, G.Z. Ramon, C.G. Dosoretz, Experimental characterization and numerical simulation of the anti-biofuling activity of nanosilver-modi fi ed feed spacers in membrane fi ltration, 475 (2015) 320-329. doi:10.1016/j.memsci.2014.10.042.

[11] J. An, J.F. Cui, Z.Q. Zhu, W.D. Liang, C.J. Pei, H.X. Sun, et al., Conductive polymercoated mesh films with tunable surface wettability for separation of oils and organics from water, J. Appl. Polym. Sci. 131 (2014) 9197-9204. doi:10.1002/app.40759.

[12] H. Sun, A. Li, X. Qin, Z. Zhu, W. Liang, J. An, et al., Three-dimensional superwetting mesh film based on graphene assembly for liquid transportation and selective absorption, ChemSusChem. 6 (2013) 2377-2381. doi:10.1002/cssc.201300319.

[13] T. Darmanin, F. Guittard, Templateless electrodeposition of conducting polymer nanotubes on mesh substrates for high water adhesion, Nano-Structures and NanoObjects. 7 (2016) 64-68. doi:10.1016/j.nanoso.2016.05.005.

[14] C.D. Vecitis, M.H. Schnoor, M.S. Rahaman, J.D. Schiffman, M. Elimelech, Electrochemical multiwalled carbon nanotube filter for viral and bacterial removal and 
inactivation, Environ. Sci. Technol. 45 (2011) 3672-3679. doi:10.1021/es2000062.

[15] M.S. Rahaman, C.D. Vecitis, M. Elimelech, Electrochemical carbon-nanotube filter performance toward virus removal and inactivation in the presence of natural organic matter, Environ. Sci. Technol. 46 (2012) 1556-1564. doi:10.1021/es203607d.

[16] R. Hashaikeh, B.S. Lalia, V. Kochkodan, N. Hilal, A novel in situ membrane cleaning method using periodic electrolysis, J. Memb. Sci. 471 (2014) 149-154. doi:10.1016/j.memsci.2014.08.017.

[17] B.S. Lalia, F.E. Ahmed, T. Shah, N. Hilal, R. Hashaikeh, Electrically conductive membranes based on carbon nanostructures for self-cleaning of biofouling, Desalination. 360 (2015) 8-12. doi:10.1016/j.desal.2015.01.006.

[18] Y. Wang, W. Li, G. Sheng, B. Shi, H. Yu, In-situ utilization of generated electricity in an electrochemical membrane bioreactor to mitigate membrane fouling, Water Res. 47 (2013) 5794-5800. doi:10.1016/j.watres.2013.06.058.

[19] H. et al Raed, Novel in-situ membrane cleaning using periodic electrolysis WO 2014117255 A1, (2014).

[20] A.T. Submitted, I.N. Partial, F. Of, T.H.E. Requirements, F.O.R. The, D. Of, et al., Modified Nafion Membranes for Hydrogen Production in $\mathrm{Cu}-\mathrm{Cl}$ Thermochemical Cycle By Naser Abdo A THESIS SUBMITTED IN PARTIAL FULFILLMENT OF, (2015).

[21] Z. Wu, H. Chen, Y. Dong, H. Mao, J. Sun, S. Chen, et al., Cleaning using nanobubbles: Defouling by electrochemical generation of bubbles, J. Colloid Interface Sci. 328 (2008) 10-14. doi:10.1016/j.jcis.2008.08.064.

[22] L. Wang, X. Wang, L. Wang, J. Hu, C.L. Wang, B. Zhao, et al., Formation of surface nanobubbles on nanostructured substrates, Nanoscale. (2017) 27906386. doi:10.1039/C6NR06844H.

[23] S.L. McArthur, Thin films of Vanadium Oxide Grown on Vanadium metal, Surf. Interface Anal. 38 (2006) 1380-1385. doi:10.1002/sia.

[24] F.E. Ahmed, B.S. Lalia, N. Hilal, R. Hashaikeh, Electrically conducting nanofiltration membranes based on networked cellulose and carbon nanostructures, Desalination. (2016). doi:10.1016/j.desal.2016.09.005.

[25] X. Sun, J. Wu, Z. Chen, X. Su, B.J. Hinds, Fouling characteristics and electrochemical recovery of carbon nanotube membranes, Adv. Funct. Mater. 23 (2013) 1500-1506. doi:10.1002/adfm.201201265.

[26] J. Shen, Q. Zhang, Q. Yin, Z. Cui, W. Li, W. Xing, Fabrication and characterization of amphiphilic PVDF copolymer ultra fi ltration membrane with high anti-fouling property, J. Memb. Sci. 521 (2017) 95-103. doi:10.1016/j.memsci.2016.09.006.

[27] S. Mokhtari, A. Rahimpour, A.A. Shamsabadi, S. Habibzadeh, M. Soroush, Enhancing performance and surface antifouling properties of polysulfone ultrafiltration membranes with salicylate-alumoxane nanoparticles, Appl. Surf. Sci. 393 (2017) 93-102. doi:10.1016/j.apsusc.2016.10.005. 